\title{
Key factors in digital literacy in learning and education: a systematic literature review using text mining
}

\author{
Catherine Audrin ${ }^{1}$ (D) Bertrand Audrin ${ }^{2}$
}

Received: 25 June 2021 / Accepted: 22 November 2021 / Published online: 10 February 2022

(c) The Author(s) 2022

\begin{abstract}
This research aims at providing an overview of the research field of digital literacy into learning and education. Using text mining, it reviews 1037 research articles published on the topic between 2000 and 2020. This review reveals that there is a plurality of terms associated with digital literacy. Moreover, our research identifies six key factors that define the literature, which are information literacy, developing digital literacy, digital learning, ICT, social media, and twenty-first century digital skills. These factors can be grouped into three main streams, which are 1) digital literacy, 2) digital learning and 3) twenty-first century digital skills. These three streams are supported by informational and technological foundations. These results provide research avenues and offer a framework for digital literacy in education.
\end{abstract}

Keywords Twenty-first century abilities $\cdot$ Information literacy $\cdot$ Text mining, digital skills and digital literacy

\section{Introduction}

With the rise of digitalization over the last decades, digital literacy has taken a central role in our society and has become an important concern for institutions and policy makers (European Commission, 2020; U.S. Department of Education, 2014). It is also a particular topic of interest for research, be it in the definition of this digital literacy (Gilster, 1997; van Laar et al., 2017) or its development (List, 2019; $\mathrm{Ng}, 2012$ ). The impact of digital society is also studied in relation to education (Di

Catherine Audrin

catherine.audrin@hepl.ch

Bertrand Audrin

bertrand.audrin@unifr.ch

1 Media, digital use and informatics didactics teaching and research unit, University of Teacher Education, Avenue de Cour 33, 1004 Lausanne, Switzerland

2 Chair of Human Resources and Organization, University of Fribourg, Boulevard de Pérolles 90, 1700 Fribourg, Switzerland 
Giacomo et al., 2017; Pinto et al., 2020) and research (Ferreira-Mello et al., 2019; Stopar \& Bartol, 2019).

In the same way that the term digital transformation covers a vast and varied set of phenomena (Audrin, 2019; Vial, 2019), there is a wide range of concepts for addressing the notions of digital skills in education literature, with some specificities and overlaps among definitions. In going beyond issues of terminology, the very purpose of research on the subject of digital literacy varies, as does the context in which it is led.

Over the last twenty years, the number of publications on digital literacy has grown almost exponentially. This abundance of scientific production is, of course, beneficial because it increases knowledge on the subject, but it also represents a significant challenge for scholars: given the proliferation of studies on the subject, it is very difficult to make sense of the field of research and to fully understand its specificities and areas of interest. Scholars benefit from using digital and quantitative research methods to give sense to the field of research. For example, Stopar \& Bartol (2019) analyze clusters of co-citations and co-citing sources to understand how research is organized. The rationale of this study is to make sense of the abundant body of literature on the theme of digital literacy in the context of education and learning. This study uses text mining to structure the field of research.

The purpose of this study is twofold. First, we want to map how digital literacy and its related notions are investigated in the context of learning and educational research. More specifically, we are interested in studying which concepts are used by researchers, and if these refer to distinct specific skills. The second purpose of this article is to study the key research streams on the topic of digital literacy and its related notions in the literature. Thus, our purpose is to both provide an overview of the field, as well as to highlight how research integrates digital literacy into learning and education. Our research questions are the following:

1) What place does digital literacy hold in the literature on education and learning?

2) How is digital literacy conceptualized in the educational context and what are the main research streams on the topic?

To answer these research questions, we conducted a systematic review of the literature using text mining (Ignatow \& Mihalcea, 2018; Thomas et al., 2011). This method is particularly suitable for our systematic literature review because it allows us to automate to a certain extent the content analysis process, and thus to process very large volumes of data in a systematic way. Text mining works by associating words or sentences and allows patterns to be extracted from a multitude of documents (Fabbri et al., 2013; Thomas et al., 2011). Our study is based on all articles published between 2000 and 2020 in English peer-reviewed journals collected on all relevant databases (Web of Science, ERIC and PsycINFO). 


\section{Methods}

As defined by Moher et al. (2015), the purpose of a systematic review is "to collate all relevant evidence that fits pre-specified eligibility criteria to answer a specific research question" (Moher et al., 2015, p. 3). A systematic review allows a clear synthesis of the characteristics and findings of the studies included in the review by adopting a systematic search to identify all studies that meet given eligibility criteria. While traditional systematic literature reviews are mostly performed manually, we propose using (semi) automatic methods. We believe that due to the huge amount of relevant literature available in the early stage of the literature review process (Ananiadou et al., 2009; Fabbri et al., 2013), researchers may benefit from the automatic extraction allowed by textual analyses (Thomas et al., 2011). Text mining is being increasingly used in research in education (Ferreira-Mello et al., 2019), as it helps provide new insights by analyzing huge quantities of information. Text mining has been used in the field of education on a variety of data, but has not been used, to the best of our knowledge, to conduct a systematic literature review on scientific articles in the field of education and on the topic of digital literacy.

Having said that, given the power of such a tool to conduct analyses on large volumes of data (such as the body of literature on digital skills in education), we believe this method could be very fruitful in order to get an understanding of the literature focusing on digital literacy in learning and education. More specifically, text mining is designed to 1) foster information retrieval, 2) extract information and 3) perform data mining by highlighting both direct and indirect associations between various pieces of information (Thomas et al., 2011). Such processes are central when conducting a systematic literature review. We thus used textual analysis to 1) filter and categorize journal articles and 2) summarize central topics emerging from these articles. Text mining allowed us to extract information about the main concepts studied in the selected articles and to organize said concepts based on their co-occurence.

\subsection{Inclusion criteria}

To select the studies included in this systematic review, we used the following criteria:

1) The article had to be published in a peer-reviewed journal and written in English. These criteria not only guaranteed scientific quality but also allowed us to gather the most important body of research focusing on digital literacy in learning and education. The language criterion was also necessary in order to perform the analysis with WordStat.

2) The article had to be published between January 2000 and November 2020. We chose 2000 as the milestone because this year represents the emerging year of the field of digital literacy in education, shortly after Gilster's seminal work on digital literacy. 
3) The study had to mention the constructs of interest (i.e. "digital*", "learn*", "educ*") in its title and/or abstract.

\subsection{Literature research strategy}

The studies were identified by searching the databases PsycINFO, Web of Science and ERIC. We searched for all available records starting from January 2000 until November 2020, using the following combination of keywords in the title or abstract of the article: "digital competenc*" OR "digital (NEAR/2) skills" OR ("digital literacy" OR "e-skills") AND ("learn*" OR "education"). We based this query on van Laar et al. (2017)'s systematic literature review. This research held an initial pool of 1460 articles. After removing duplicates, there were 1037 articles left.

\subsection{Data analysis}

We performed text mining with the software WordStat 8 on the titles and abstracts of the 1037 articles selected in the previous section. WordStat is a software that offers quantitative analysis of textual data (Pollach, 2011). Through dictionaries, it allows to explore a corpus of texts and to identify key factors underlying said corpus. Recent literature reviews have been realized using WordStat (Ćurlin et al., 2019; Jede \& Teuteberg, 2015). As specified by Durach et al. (2017), researchers performing a literature review are required to summarize the findings of the different studies. Relying on a textometric analysis allows for more objectivity in summarizing studies as researchers do not intervene in the coding and thus, do not tend to introduce biases during the analysis, coding and synthesis of the literature review.

The principle of text mining is that "the frequency with which a content word appears, the statistical relationships between content words and their context all witness to thematic patterns specific to a corpus" (Lavissière et al., 2020, p. 136). Our textometric analysis uses both processes of stemming and lemmatization. Stemming compiles and removes derivations and inflections of words to gather them into roots - or stems. We used Lovins' algorithm (Allahyari et al., 2017; Vijayarani et al., 2015). Lemmatization identifies the basic form of the words used in the corpus and relates them to their dictionary form. It thus returns to the lemma of the world, which is the dictionary form of a given word (Schütze et al., 2008).

Thus, our analysis first consisted in assessing the frequency of phrases across titles and abstracts in our corpus of articles. Then, we performed a co-occurrence analysis on the frequencies of phrases in titles and abstracts. Such analysis is based on the construction of a specific dictionary for the corpus. We built this dictionary based on the results of the frequency analysis. Items were included in the dictionary if they 1) occurred more than 100 times and 2) were directly related to learning, education and digital technologies. This dictionary accounted for $11.4 \%$ of the total words of the whole corpus. When considering excluded words (such as "a", "the", etc.), our dictionary accounted for $96 \%$ of the corpus. This analysis allowed us to find common phrases in our corpus, and further to perform factor analysis, multidimensional scaling and link analysis on our data. Note that we considered "phrases" 
to be the sequence of two to eight co-occurring words. We used the Phi coefficient to measure the association between words, as its interpretation is similar to the Pearson correlation coefficient. We selected the second order clustering method, as it is based on the idea that two words are close to each other, not necessarily because they occur near each other or in a same document, but because they occur in similar environments.

Finally, we performed a latent semantic analysis by applying a factor analysis with Varimax Rotation in order to extract a small number of factors from synthesizing the data. Data was segmented between documents, meaning that the topic modeling used was based on the cooccurrence of words in one article (its title and abstract). Phrases that occurred less than 30 times were removed, as it is advised to ensure the stability of the factorial solution. We selected factors which accounted for at least $20 \%$ of the cases. To define our factors, we retained words whose loadings (standardized link between a word and its factor) were higher than .3. We chose to perform a factor analysis instead of a hierarchical cluster analysis given that in a factor analysis one word may be associated with more than one factor, which we believe is more realistic. Indeed, this may not only reveal the polysemous nature of words but also highlight that some words may appear in multiple contexts.

\section{Results}

\subsection{An ever-growing proliferation of publications in numerous journals}

Results reveal a growing interest in the study of digital literacy and education, as reported in Fig. 1. This figure reveals that very few studies were published on the

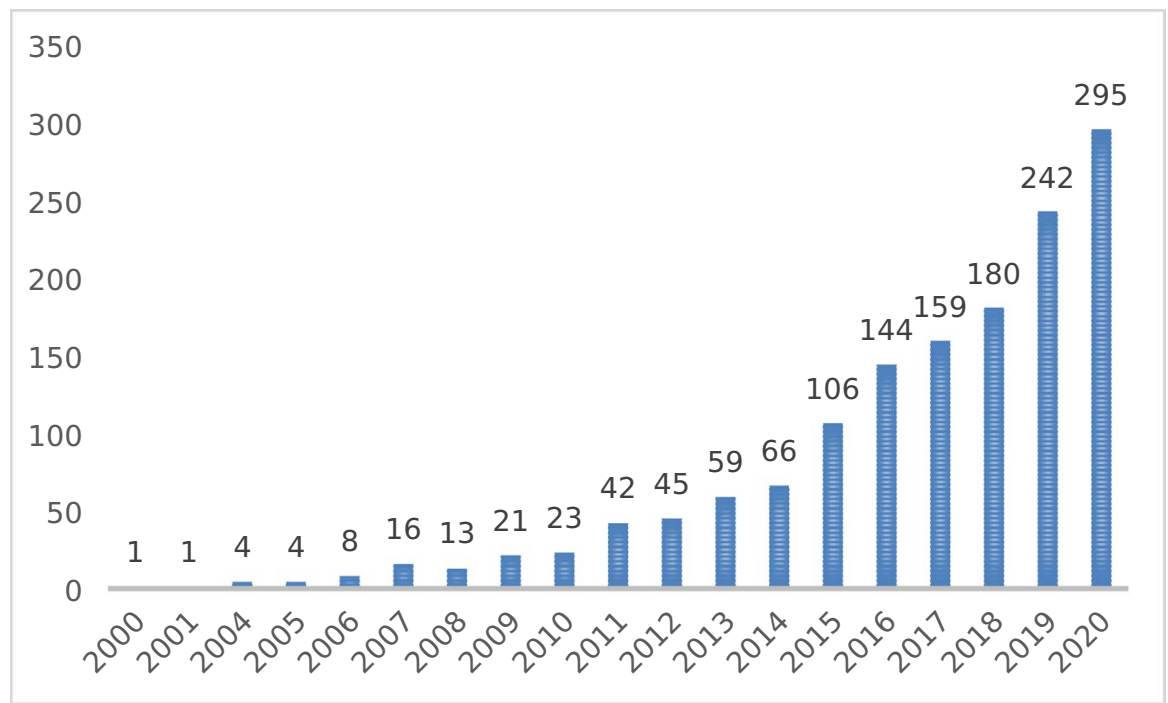

Fig. 1 Number of publications by year 
topic of digital literacy and learning in 2001, while almost 300 articles were published on this topic in 2020. These results can seem logical and obvious, as digitalization as such is quite a recent concept that has really boomed over the last decade. It shows, however, how research adopts a topic and makes it a fundamental topic of research in a relative short span of time, as illustrated by the progression between 2011 (42 articles published) and 2019 (242 articles published). More precisely, we can say that a threshold has been crossed in 2015 when the number of publications got higher than a hundred in a year, almost doubling the numbers from the previous year. The numbers for the next few years confirm this trend, highlighting the growing importance of digital literacy and its relevance for research.

Four journals have published more than 20 papers on the topic, with "Computer \& Education" leading at 41 articles and "International Journal of Digital Literacy and Digital Competence" following with 27 articles. Behind these big contributors, there is a very high number of journals that have published on the topic. The topic of digital literacy and learning is not limited to journals in the field of education but is also studied in other fields such as medicine and health, technology, organizational behavior, and so on. This highlights how digital literacy as a topic is widespread in literature, appearing in numerous journals with several terminologies, research angles, methods, and concerns that strongly differ.

\subsection{A plurality of terms}

We now turn to the content of our analysis itself. In Table 1, we report a frequency table of the phrases which were mostly cited across all articles. As specified in the methods section, we considered "phrases" to the sequence of at least two co-occurring words. Phrases were kept if they occurred more than 100 times in the data. This table clearly highlights that "digital literacy" is a central concept, as it occurred 1734 times within 849 articles of our corpus of 1037 articles. It is then followed by "digital competence" (556 occurrences among 235 articles), "digital skills" (455 occurrences among 308 articles), and "digital competencies" (255 occurrences among 148 articles).

A first striking point is to notice the plurality of the terms used on this topic. This point has already been highlighted in various literature reviews on the topic (Aviram \& Eshet-Alkalai, 2006; Spante et al., 2018), where scholars have tried to decipher the relationships between e-skills, digital literacy, information and communication technology (ICT) literacy, digital skills, digital competence, and so on. The biggest issue when trying to make sense of the relationships between such a variety of terms is to understand to which extent they are similar or distinct. By going back to the very definitions of the concepts used in the literature, we can note some differences in the way the concepts are defined and used.

Definitions of digital literacy are numerous in education literature, but all trace back to the original definition suggested by Gilster (1997) who defines digital literacy as "the ability to understand and use information in multiple formats from a wide range of sources when it is presented via computers" (Gilster, 1997, p.1). This definition offers a very interesting starting point as to what digital literacy 
Table 1 Frequency of phrases across articles - generated by WordStat

\begin{tabular}{llllll}
\hline & Frequency & No. Cases & $\%$ Cases & Length & TF • IDF \\
\hline Digital literacy & 1734 & 849 & $59,41 \%$ & 2 & 392,1 \\
Digital competence & 556 & 235 & $16,45 \%$ & 2 & 435,9 \\
Digital skills & 455 & 308 & $21,55 \%$ & 2 & 303,2 \\
Digital competencies & 255 & 148 & $10,36 \%$ & 2 & 251,1 \\
Higher education & 253 & 148 & $10,36 \%$ & 2 & 249,1 \\
Digital technologies & 204 & 124 & $8,68 \%$ & 2 & 216,6 \\
Digital literacy skills & 185 & 108 & $7,56 \%$ & 3 & 207,5 \\
Twenty-first century & 160 & 92 & $6,44 \%$ & 2 & 190,6 \\
Case study & 154 & 116 & $8,12 \%$ & 2 & 167,9 \\
Social media & 146 & 73 & $5,11 \%$ & 2 & 188,6 \\
Teacher education & 143 & 69 & $4,83 \%$ & 2 & 188,2 \\
Digital divide & 140 & 69 & $4,83 \%$ & 2 & 184,3 \\
Young people & 137 & 68 & $4,76 \%$ & 2 & 181,2 \\
Information and communication & 134 & 115 & $8,05 \%$ & 3 & 146,6 \\
Information literacy & 129 & 53 & $3,71 \%$ & 2 & 184,6 \\
Pre service & 129 & 43 & $3,01 \%$ & 2 & 196,3 \\
Digital media & 125 & 76 & $5,32 \%$ & 2 & 159,3 \\
Digital technology & 120 & 88 & $6,16 \%$ & 2 & 145,3 \\
Teaching and learning & 112 & 100 & $7,00 \%$ & 3 & 129,4 \\
Digital literacy practices & 106 & 63 & $4,41 \%$ & 3 & 143,7 \\
Students digital & 103 & 72 & $5,04 \%$ & 2 & 133,7 \\
Digital tools & 102 & 60 & $4,20 \%$ & 2 & 140,4 \\
\hline
\end{tabular}

Note: $T F$, term frequency; $I D F$, inverse document frequency

encompasses by emphasizing that digital literacy is not only about technical skills but also encompasses a cognitive dimension (van Laar et al., 2017; Spante et al., 2018). Avila and Pandya (2013) further emphasize the critical-thinking dimension of digital literacy by coining the term "critical digital literacies" (Avila \& Pandya, 2013, p. 3). Other scholars such as Aviram and Eshet-Alkalai (2006); $\mathrm{Ng}$ (2012); Tuamsuk and Subramaniam (2017) even go beyond in suggesting that there is another dimension to digital literacy, which is the socio-emotional dimension. In this perspective, digital literacy also integrates online behaviors and the sensibility that is required to behave appropriately (Eshet, 2004). One of the first things that is striking when comparing these definitions is that there is no consensus on the actual definition of digital literacy. Scholars agree that digital literacy goes beyond technical aspects to include cognitive aspects. Beyond that, digital literacy appears as a multifaceted notion with some scholars emphasizing specific elements and others emphasizing others.

The second most recurring term in our corpus is "digital competence" or "digital competencies". It is broadly defined by Picatoste (2018) as "a set of different skills for achieving a good performance on digital society" (Picatoste et al., 2018, p. 1033). This definition is interesting because it emphasizes the 
notion of performance. Other existing definitions of digital competence further insist on the notion of technology use (Scuotto \& Morellato, 2013) and knowledge production (Cazco et al., 2016). These definitions are interesting because they articulate digital competence around practical aspects of using digital tools. In contrast, digital literacy seems to be focusing more on processing and communicating information.

The third term that appears most frequently in our corpus is "digital skills". Here again, the term has been widely used in the literature and many definitions exist. Van Dijk for example defines digital skills as the "set of skills that users need to operate computers and their networks, to search and select information, and the ability to use them for the fulfillment of one's goals" (van Dijk, 2006, p.73). This definition distinguishes three dimensions of digital skills: technical skills (i.e. the ability to operate a computer or other kinds of digital technologies), information-seeking skills (i.e. ability to browse and select relevant information), and strategic skills (i.e. using technical and information skills in order to achieve something) (van Dijk, 2006). van Deursen and van Dijk (2009) further make a distinction between the technical aspects and the content aspects in the digital skills to account for the specificities of online content. The way digital skills are defined in the literature seems to put emphasis on both the technological and medium of communication aspects.

Table 1 further highlights that the term 'twenty-first century' appears 160 times. This term can be associated with twenty-first century skills or twentyfirst century digital skills, terms that have been made popular by van Laar et al. (2017, 2019). They provide a framework for defining twenty-first century digital skills as it identifies seven core skills, which are technical, information management, communication, collaboration, creativity, critical thinking and problem solving. Twenty-First century digital skills as such, consist of a broad array of competencies that are crucial in order to successfully accomplish tasks in the digital twenty-first century. Van Laar and colleagues further study how some determinants such as education level, age, and social support influence 21 st digital skills, and are as such needed to be taken into account by educators and policy-makers (van Laar et al., 2019).

Based on Table 1 and on the definitions available in the literature, it appears that there is a multiplicity of overlapping concepts in education literature, all of which have their specificities and their particular inclinations. The pervasiveness of various terms such as digital literacy, digital competence(s), digital skills, and twenty-first century digital skills casts doubt on the overall appropriateness of use of the terms in the literature. It raises questions about the extent to which scholars use them with a specific intent in mind, with Fieldhouse and Nicholas (2008) noting that terms are often interchangeable in taking the example of 'literacy', 'fluency', and 'competency'. Table 1 highlights the breadth and heterogeneity of the terminology used in the literature; the results of our co-occurrence analysis emphasize this global lack of precision in the terminology and in its use. 


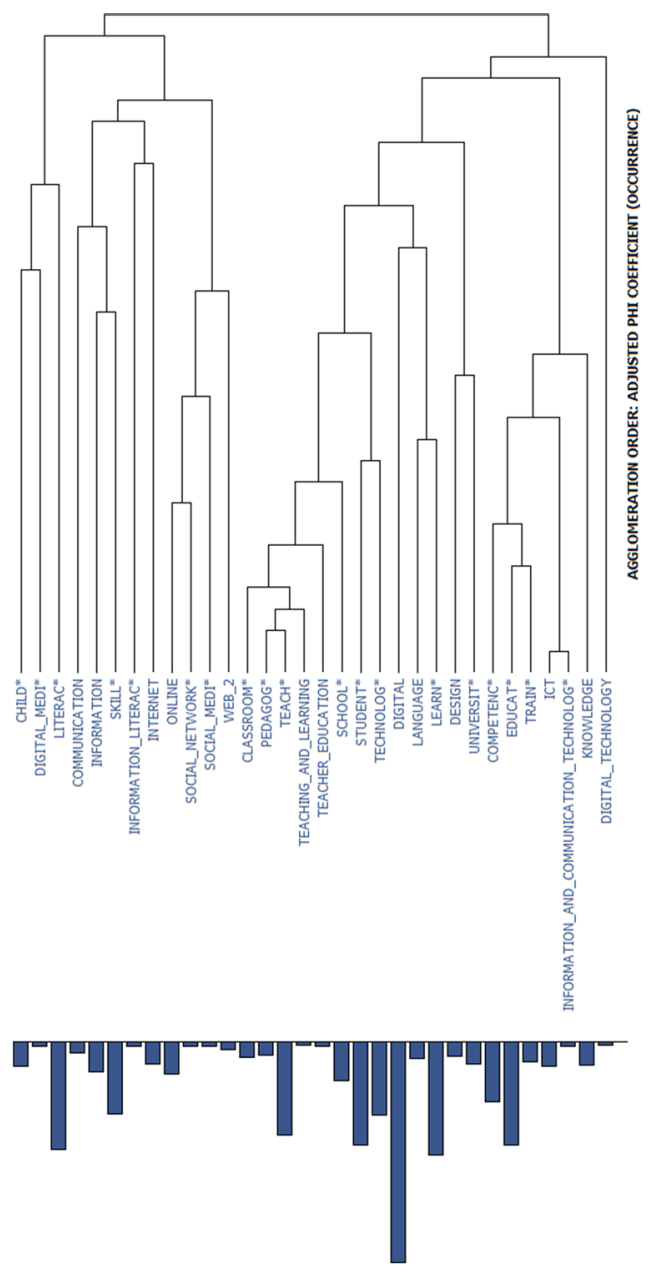

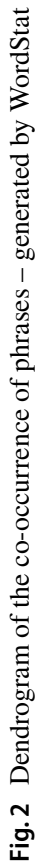




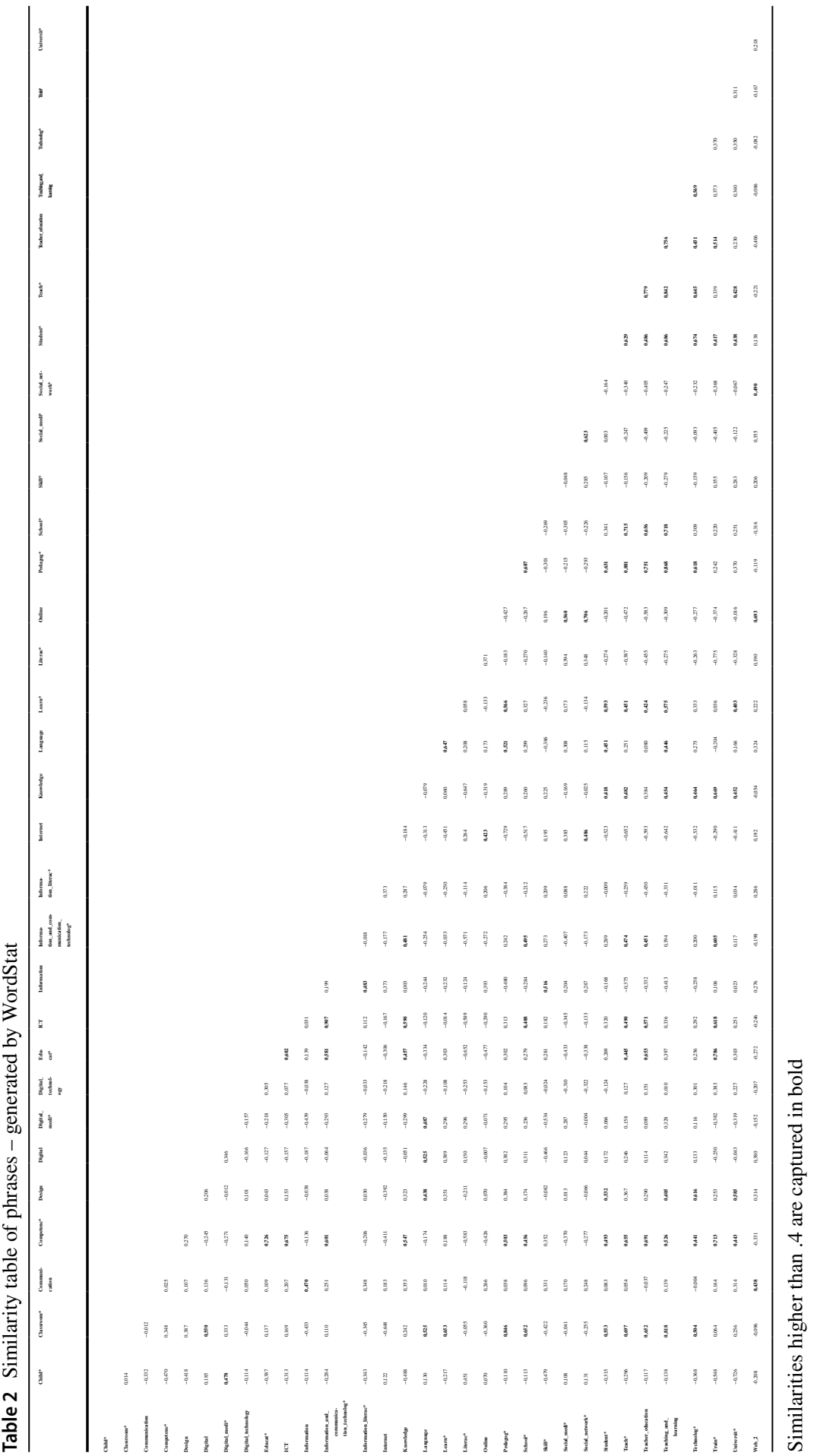




\subsection{Co-occurrence analysis: Classroom versus everyday life}

In the following section, we report the results of a co-occurrence analysis based on the frequencies of phrases in titles and abstracts. Figure 2 represents a dendrogram describing the similarities between the phrases, and Table 2 shows a table of similarity, where the coefficients can be interpreted as correlation coefficients. Note that the values of the coefficients are not based on the frequencies of the words but rather on the co-occurrences of specific words in a case.

Two main groups of phrases can be extracted from the dendrogram and from the similarities table. On the one hand, themes related to information literacy, digital media, literacy and social media appear to form one group of concepts. Indeed, social media and social networks are related to "online" (both phi higher than .5) and "internet" (phi $=.486$ ). Surprisingly, the term "internet" is negatively associated with concepts related to learning and education (such as "pedagogy", phi $=$ -.729 ; teaching, phi $=-.652$, teaching and learning, phi $=-.642$, school, phi $=$ -.517 and student, phi $=-.523$ ). This leads us to the second main group of phrases, which are related to the classroom. This group includes phrases such as "learning", "language", "pedagog*", "school", "student", "teach*, "teacher education", "teaching and learning", which all have an association higher than .5 with the concept of "classroom". These terms are also strongly related with the term "competence" (association higher than .4). Moreover, competence is strongly related to "train*" $(\mathrm{phi}=.713)$ and "universit*" (phi $=.443)$.

This dendrogram provides a visual representation of how the terms in our corpus are associated. It is interesting to note that two groups of phrases emerge, with terms associated with the educational and learning environment on the one hand, and those with a more practical focus on the other. We can therefore distinguish in our corpus a literature that deals with the development of digital skills from a literature that focuses on the operationalization of such digital skills. Figure 2 therefore displays two major research streams on digital literacy.

\subsection{Factor analysis}

Results of the factor analysis highlighted 6 factors, all of whom had eigenvalues higher than 1. Results are described in Table 3 below, where factors are sorted by importance of eigenvalues.

The first factor highlighted in the factor analysis (eigenvalue $=2.48$ ) refers to the importance of information (loading $=.566$ ) and information literacy (loading $=$ .534). This factor highlights how information and communication are central in the literature on digital literacy. The keywords associated with this factor really highlight the central role of information and communication, which can be considered as the 'informational base' of digital literacy. Information and communication are the two fundamental foundations at the source of digital literacy. Our analysis also highlights other keywords emphasizing the importance of information channels, with keywords such as digital information, information sources, or health information. 
There is a strong body of research that focuses on that technological base and on the multiplicity of tools that are available in the education context (see Pinto et al., 2020 for a review). Actions such as gathering and transmitting information and communicating efficiently, communicating through presentations and video-images, collaborating and working with documents online through mobile devices are the essence of digital literacy (Vázquez-Cano et al., 2020). The fact that this is the most important factor in our corpus confirms the importance of information and communication as the two major pillars of digital literacy.

The second factor (eigenvalue $=1.97$ ) refers to the importance of digital (loading $=.466$ ) literacy (loading $=.672$ ). Central themes to this factor are digital literacy, digital skills and competence as well as digital technologies. The fact that these three terms are grouped within the same factor confirms the inclination already highlighted in our descriptive analysis to use indifferently the terms of digital competence, digital literacy or digital skills. While these terms are supposed to be used in different fields of application, they are combined in the same factor, related to the educational context for the acquisition of digital literacy. This factor focuses on the development of digital literacy, being related with keywords such as classroom (loading $=.389)$ and pedagogy (loading $=.227$ ). We name this factor "developing digital literacy - how to become digitally literate".

Among the selected articles in our review, several highlight the importance of teaching digital skills (Peláez et al., 2020) and propose specific programs to developing (critical) digital literacy pedagogies (Alt \& Raichel, 2020; Campbell \& Kapp, 2020; Handley, 2018; Knight et al., 2020). Other studies highlight that pupils (Pérez-Escoda et al., 2016), students (Al Seghayer, 2020) but also adults and teachers (Eynon, 2020; Martín et al., 2020; Sillat et al., 2017) need support to use digital tools, while Bergdahl et al. (2020) suggest that digital skills are related to students' engagement in (technology-enhanced) learning and learning outcomes (Pagani et al., 2016). This factor not only highlights the importance of digital literacy and the fuzziness surrounding the terminology, but further emphasizes the acquisition of such competence in an educational context. While this is crucial for pupils, the implementation of such digital literacy pedagogies strongly relies on the teachers' digital skills (Fernández-Cruz \& Fernández-Díaz, 2016), revealing that there is a gap between teachers' actual skills and the optimal skills required for them to efficiently propose learning activities using technological tools. Moreover, the (intention to) use ICT in their courses is strongly related to: teachers' motivation (Guillén-Gámez et al., 2019) and attitudes towards ICT (Area-Moreira et al., 2016; Nuzzaci, 2017; Siddiq et al., 2016), teaching approach (Mirete et al., 2020), ICT school equipment (Lorenz et al., 2019) as well as ICT school culture (Blau \& Shamir-Inbal, 2017). Thus, many scholars (Fernández-Cruz \& Fernández-Díaz, 2016; Gómez-Trigueros et al., 2019; Gudmundsdottir et al., 2020; Martín et al., 2020; Mynaříková \& Novotný, 2020; Sillat et al., 2017; Tømte, 2015) advocate that teacher training should focus more on the vocational teachers' development of digital skills, notably by integrating ICT in their curriculum (Pombo et al., 2017).

The third factor (eigenvalue $=1.63$ ) was named "digital learning" as two terms were central to the definition of this factor: learning (loading $=.627$ ) and university (loading $=.532$ ). Notably, results suggest that digital tools are often used in 


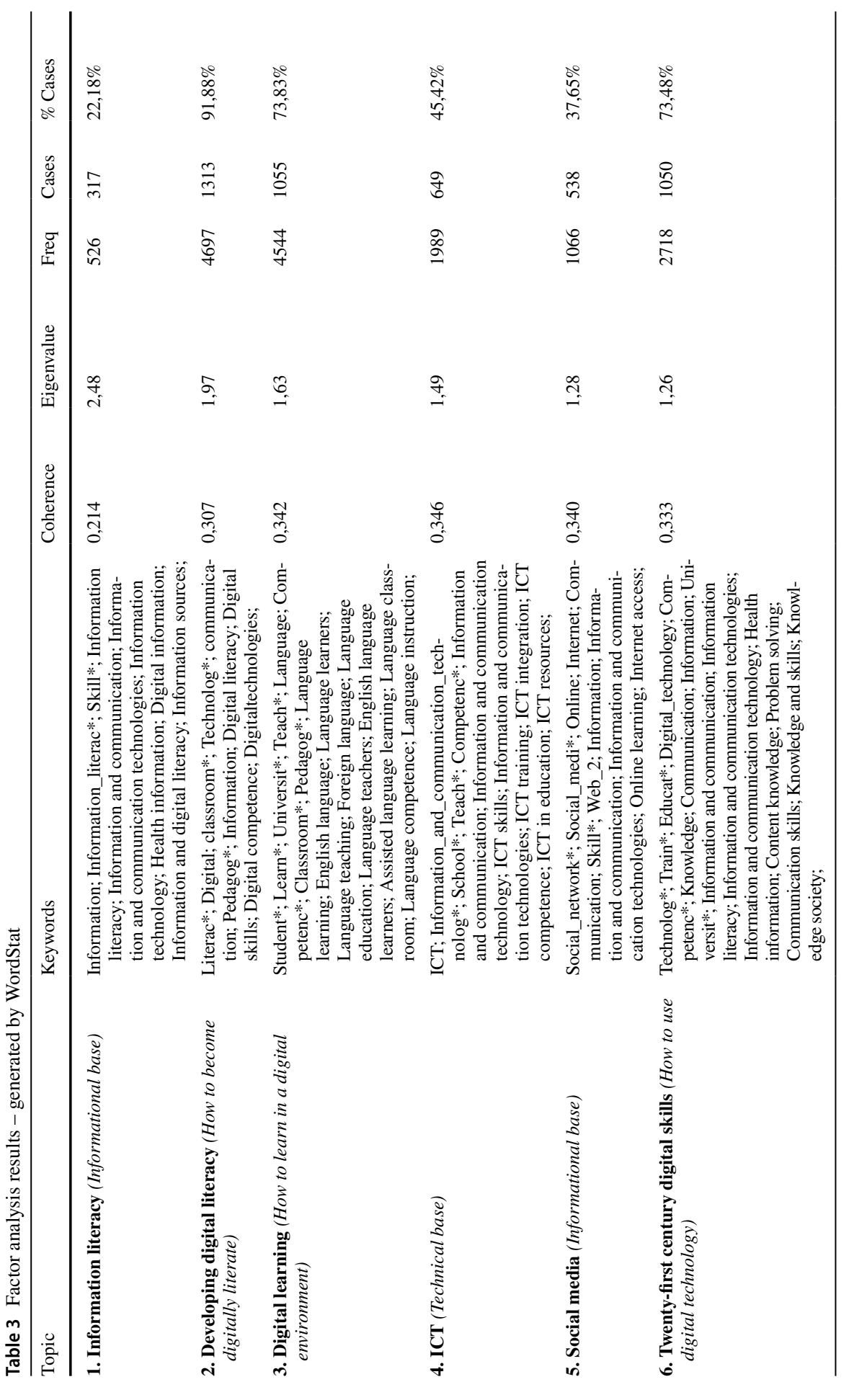


the context of language learning (loading $=.287$ ) - central themes of this factor are "language learning", "language teaching", "foreign language", "language education", "language competence" and "language education". This shows that digital technologies are used and relevant in the context of learning (Alvermann et al., 2012): digital tools are used to foster learning of languages (Dixon, 2010), reading (Daley et al., 2020) but also mathematics (Gómez-García et al., 2020).

This factor also defines another context in which digital technologies are used to foster learning in higher education, as "university" has a loading of .532. Numerous digital learning initiatives have been carried out at the higher education level (e.g. Blayone et al., 2018; Hardy \& McKenzie, 2020; Spante et al., 2018; Tejedor et al., 2020). Despite such enthusiasm, Liesa-Orús reveal that university professors may also benefit from training in the acquisition of digital skills (Liesa-Orús et al., 2020).

Thus, factor three highlights how one can learn thanks to digital technologies. In contrast to factor two, which was named "developing digital literacy", factor three focuses on the use of digital technologies as a tool to foster not only learning but also cognition in general (Di Giacomo et al., 2017).

Factor four (eigenvalue $=1.49$ ) highlights the importance of information and communication technologies (loading $=.660$; ICT loading $=.739$ ) and links it to the educational environment (teaching, loading $=.397$, school, loading $=.464$ ). This factor highlights the technological foundations required for the development of any educational initiative that aims at using or developing information and communication skills (Gómez-García et al., 2020). Factor four has to be considered in relation to factor one, which emphasizes the information and communication dimensions that are at the basis of digital skills. In the same way, this factor emphasizes the technological infrastructure necessary for the development of digital skills, which can be considered as part of the 'technological base' of digital literacy. Several articles report the implementation of ICT in various curricula such as in primary schools (Borysenko et al., 2020), and secondary schools (Dzhurylo \& Шпарик, 2019), as well as with special needs students (Rivera et al., 2017), while others compare ICT vs. non-ICT settings (Arrosagaray et al., 2019). When information and communication are the basic activities requiring technological skills, information and communication technologies are the tools that will enable the development of these skills.

Factor five (eigenvalue $=1.28$ ) highlights the media dimension of digital technologies. Notably, social network (loading $=.534$ ), social media (loading $=.500$ ), online (loading $=.499$ ), internet (loading $=.425$ ) and web 2.0 (loading $=.249$ ) are important words associated with this factor. Factor five focuses on a specific aspect of digital communication tools that is social media, which can be considered as another part of the "technological base" of digital literacy. Social media represents a cornerstone of digital communication and requires digital literacy (Durak \& Seferoğlu, 2020): interacting with people on social networks, gathering information, communicating, etc., all these activities require digital literacy. In a way, this factor refers to the operationalization context of digital skills in everyday life. Various studies highlight the importance of social media in everyday life (e.g. Akayoglu et al., 2020; Correa, 2016), further revealing that their use may foster digital skills (Cole et al., 2017; de Mesa \& Jacinto, 2020) and learning (Rwodzi et al., 2020), and thus, could be used as a teaching tool (Dennen et al., 2020). Interestingly, they 
suggest that while social media is strongly used, users nevertheless appreciate when guidance is provided by their learning environment (Akayoglu et al., 2020) or more generally by the social structure they are part of (Eynon \& Geniets, 2016). Moreover, these results further highlight the importance of education in 1) the use of social media (Correa, 2016) and 2) the resources that can be mobilized from the internet (van Ingen \& Matzat, 2018).

The last factor (eigenvalue $=1.26$ ) highlights the importance of technology (loading $=.549$ ) in education (loading $=.405$ ) and training (loading $=.455$ ) and links digital technology (loading $=.379$ ) and knowledge (loading $=.305)$. Central topics are "content knowledge", "knowledge and skills", "knowledge society", "communication skills" and "problem solving". This conjunction of keywords seems to be quite in line with the central components of twenty-first century digital skills. Thus, we name this factor " 21 st century digital skills" to connect this factor with the education literature and to emphasize the importance of the capacity to interact with digital technology. Indeed, this factor regroups keywords focusing on how people may use technology not only to foster knowledge (Higgins, 2014), but also to deal with specific issues, to (collectively) solve problems (Sun et al., 2020), show critical thinking (Cladis, 2020; Higgins, 2014; Kivunja, 2014; Novakovich, 2016) and to communicate. Studies highlight the importance of the educational context to foster such competences (Petrucco \& Ferranti, 2017), notably through the development of a critical pedagogy (Coker, 2020) and teaching intervention to highlight skepticism (Walton et al., 2018). Thus, this factor refers to questions such as "what is the end goal of digital literacy?" and "how/for what can we use this competence in everyday life?", falling well in line with van Laar and colleagues' definition of what the twenty-first century digital skills are about.

It is important to analyze Tables 3 and 4 jointly in order to keep in mind the continuity between the keywords, the factors, and their correlations. Table 4 below reports the correlation between latent factors. Values higher than 0.4 are highlighted in bold. These correlations reveal that latent factors may be grouped into two main groups. The first group combines the factors digital learning, digital literacy, ICT, and twenty-first century digital skills. Considering the items that these factors gather and the relationships among them, it appears that this first group mainly involves factors related to learning and the educational environment. The second group includes twenty-first century digital skills, information literacy, and social media. Given the keywords that form these factors, this second group consists of factors with a greater practice orientation. It is interesting to note that twenty-first century digital skills bridge the two groups, and somehow connects the classroom to everyday life.

\section{Discussion}

The purpose of this review was to provide an overview of the research field of digital literacy into learning and education. More precisely, it aimed at answering the following two questions: 1) What place does digital literacy hold in the literature on 
education and learning? 2) How is digital literacy conceptualized in the educational context and what are the main research streams on the topic?

Using text mining, this review maps the field of educational research in line with digital literacy. A number of 1037 studies performed between 2000 and 2020 on this topic were included, as they explicitly mentioned digital skills (or related terms such as digital literacy or competence), education and learning either in their title and/or in their abstract. This number of studies shows that there is a great deal of interest in this topic. The first question that this rapid growth raises is that of the sustainability of this research area: is digital literacy a long-lasting research topic or is it going to be out-of-date in a few years because of the emergence of new technologies? On one hand, the fact that digital literacy is tightly linked to ICT and digital media suggests that it might not be relevant in a post-digital world. On the other hand, the very concept of digital literacy is more than twenty years old and still relevant, even if technological evolution has been tremendous over that period of time. Moreover, the concept of digital literacy covers more than the sole technical dimension, which suggests that research on the subject still has a long way to go.

Our analysis suggests that the terms used (most notably, digital skills, digital literacy, digital competence(s)) need to be clearly defined, as authors tend to use them interchangeably although each term has its own specificities. These results are consistent with other literature reviews (Spante et al., 2018). The relative youth of the literature field (about twenty years old) might explain why the terminology is not yet fully established. Nonetheless, this may generate some confusion and potential misunderstandings, as well as a dispersion in the field of research. Our descriptive results shed light on this plurality and our analysis of the corpus provide an overview of the research field and highlights how research integrates digital literacy into learning and education. This allows researchers to better position their research on the subject and to use the appropriate terminology.

Our research allows us to go beyond the issues of terminology to offer a mapping of the field of research in education sciences on digital literacy. Text mining allows us to give an overview of the field, but also to investigate in detail the different elements that compose it.

Our results highlight a fragmentation in this field: on the one hand, there are studies focusing on digital literacy in an educational context (i.e. in classrooms and other learning contexts). On the other hand, there is research highlighting practical aspects related to digital world, such as the use of social media and social network and more generally to information literacy. This fragmentation of research in this field is in line with Stopar and Bartol (2019) who also identify distinct research clusters. This allows us to identify three main streams of research, namely: learning digital literacy, digital learning and twenty-first century digital skills, as well as two fundamental dimensions that support the digital ecosystem that are the informational and the technological base.

Digital literacy and digital learning are at heart of the research field, as they constitute its core focus. Research is booming and there are more and more studies investigating either the development of digital literacy or digital learning setups. There is a high correlation between these two research streams, but more research needs to be led in order to combine these two research streams. Research 


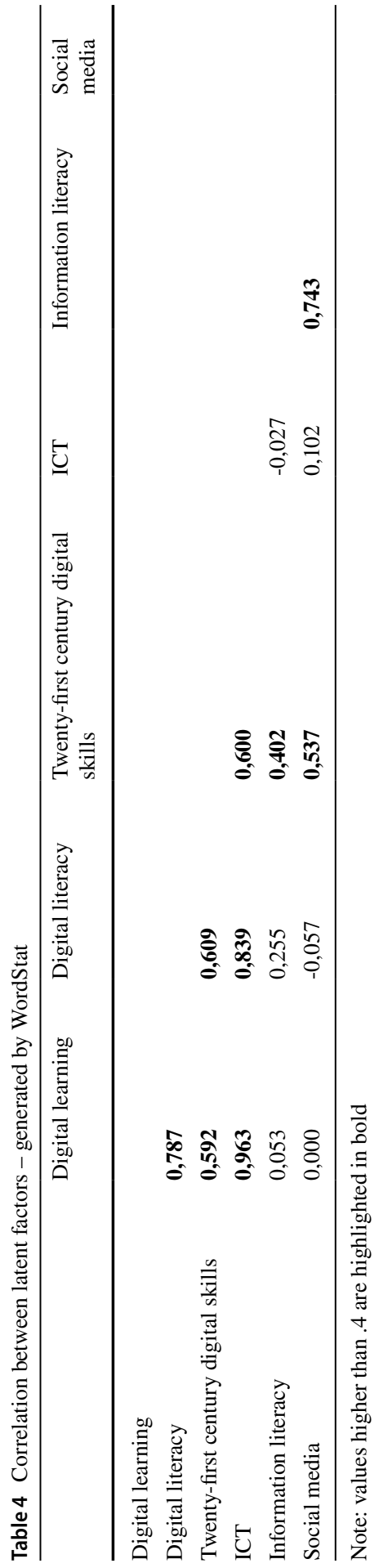


could for example focus on how digital literacy enables digital learning, or, at the opposite, how digital learning creates a fruitful environment to develop digital literacy (e.g. Cazco et al., 2016; Hatlevik, 2017; Yu et al., 2017). Research could also specifically target vocational teachers, as their role in both fostering digital literacy and creating digital learning environments are crucial (e.g. Area-Moreira et al., 2016; Gómez-Trigueros et al., 2019; Gudmundsdottir et al., 2020; GuillénGámez et al., 2019; Martín et al., 2020; Mynaříková \& Novotný, 2020). Research also advocates that teacher training should focus more on the vocational teachers' development of digital skills, notably by integrating ICT in their curriculum (Pombo et al., 2017).

The twenty-first century digital skills factor shows another axis of research in the literature field bridging the technological base and the informational base. Rather than asking the question of digital learning or learning digital literacy, the issue here is the operationalization of these skills between technology and information and communication. This factor therefore illustrates a third research axis in the literature on digital skills, which is more concerned with understanding what these digital skills are made of and how they can be used in everyday life. Research in this stream can step out of the traditional education and learning field of research to tackle other issues related to twenty-first century digital skills, for example in the workplace (van Laar et al., 2019).

The technological aspect is very important and can be found in the ICT and social media factors. They represent the "technological base" without which the whole digital ecosystem would not exist, demonstrating their central role in research. The particularity of digital communication tools is that they are constantly evolving, which is why studies focusing on tools are always relevant as they deal with a constantly evolving reality that needs to be understood. The social media factor, beyond its technological dimension, also has to be linked to its daily life dimension in which social media is used for all kinds of activities. This factor therefore has an embeddedness in daily life that is important to take into account.

Information and communication are also a key element of this research area, constituting what could be called the "informational base" without which the whole digital ecosystem does not exist. In this sense, the information literacy factor puts the emphasis on data and on information and communication, which are the core forms of expression in digital literacy. The performance of information and communication tasks is at the heart of digital literacy, and this "informational base" appears in both research streams.

Our study has several limitations. The first limitation is methodological in nature and concerns text mining. In contrast to traditional systematic literature reviews which focus on the most relevant articles by establishing very precise selection criteria and analyze them in depth, our approach via text mining aims rather at processing a very large number of articles (the whole body of articles published on the topic) and analyzing them in an automated way. This does not allow us to obtain the depth of analysis of traditional systematic literature reviews, but it is very useful in order to have a global understanding of the field of research. This objective of mapping the entire literature is incompatible with a more in-depth work on the content of the articles. Future studies, however, could dig deeper into the factors that have 
been identified in our analysis and analyze how these operate in the field of research in order to make sense of their specificities.

Another issue with text mining is that it works through keywords and can thus miss important topics if they are not signaled through the appropriate keywords. For example, private context does not appear in our analysis, even though there is an important body of literature that highlights the importance of personal factors. This literature focuses on children's first use of ICT (Juhaňák et al., 2019), cultural background (Gui \& Argentin, 2011), socioeconomic status (Hatlevik et al., 2015; Jara et al., 2015; Zhong, 2011), parental active mediation of ICT use (Livingstone et al., 2017), parental level of education (Cabello-Hutt et al., 2018). The absence of this dimension in our analysis might be explained by the fact that there is no term that encompasses all these sub-themes, no keyword that the automatic analysis could retrieve. This factor, however, plays an important role in the research as it seems to be a determinant of digital literacy.

Finally, one limitation of our study is its focus on education. This focus on educational research allows us to have a comprehensive view of the whole field, but limits our understanding of digital skills and their applications in daily life and notably within the world of work. Future studies could aim at bridging the classroom with the workplace in order to have a more global perspective on digital skills and results that benefit both (Ahlquist, 2014; Alvermann et al., 2012; Kivunja, 2014).

\section{Conclusion}

This research aimed at providing an overview of the research field of digital literacy into learning and education. Using text mining, we reviewed 1037 research articles published on the topic between 2000 and 2020. This review reveals that there is a plurality of terms associated with digital literacy: researchers tend to use the terms "digital literacy", "digital skills", "digital competence" and " $21^{\text {st }}$ century digital skills" interchangeably when these should be used with a grain of salt.

Our results further emphasize the fragmentation of research between studies performed in the classroom vs. research focusing on everyday life digital skills. Future studies should build on the 21st century digital skills to bridge both universes.

Finally, our research identifies six key factors that define the literature. These factors can be grouped into three main streams, which are 1) digital literacy, 2) digital learning and 3) 21st century digital skills. This review not only highlights the importance of individuals' development of digital literacy, but also sheds light on the critical role of digital technologies in education. The 21 st century digital skills factor offers a wider perspective on the use of digital literacy beyond the educational context. These three streams are supported by informational and technological foundations, further emphasizing the role of information and technology in this topic: research on digital literacy cannot be untied from its informational and technological prerequisites. This study suffers from several limitations. On a methodological level, text mining only allows for a surface analysis of the field and may miss some keywords. On a more general level, we focused on the field of education 
only, even though digital literacy is also relevant in other areas of research such as management.

Acknowledgements We would like to thank our parents for their continuous support and guidance.

\section{Declarations}

Conflict of interests/competing interests The authors declare no conflict of interest.

Open Access This article is licensed under a Creative Commons Attribution 4.0 International License, which permits use, sharing, adaptation, distribution and reproduction in any medium or format, as long as you give appropriate credit to the original author(s) and the source, provide a link to the Creative Commons licence, and indicate if changes were made. The images or other third party material in this article are included in the article's Creative Commons licence, unless indicated otherwise in a credit line to the material. If material is not included in the article's Creative Commons licence and your intended use is not permitted by statutory regulation or exceeds the permitted use, you will need to obtain permission directly from the copyright holder. To view a copy of this licence, visit http://creativecommons.org/licen ses/by/4.0/.

\section{References}

Ahlquist, J. (2014). Trending now: Digital leadership education using social media and the social change model. Journal of Leadership Studies, 8(2), 57-60.

Akayoglu, S., Satar, H. M., Dikilitas, K., Cirit, N. C., \& Korkmazgil, S. (2020). Digital literacy practices of Turkish pre-service EFL teachers. Australasian Journal of Educational Technology, 36(1), 85-97 https://doi.org/10.14742/ajet.4711

Al Seghayer, K. (2020). Investigating the adequacy of EFL Learners' L2 digital literacy skills, consistency of self-assessed competence, and actual performance. International Journal of ComputerAssisted Language Learning and Teaching, 10(2), 1-22 https://doi.org/10.4018/IJCALLT.20200 40101

Allahyari, M., Pouriyeh, S., Assefi, M., Safaei, S., Trippe, E. D., Gutierrez, J. B., \& Kochut, K. (2017). A brief survey of text mining: Classification, clustering and extraction techniques. ArXiv Preprint ArXiv, 1707, 02919.

Alt, D., \& Raichel, N. (2020). Enhancing perceived digital literacy skills and creative self-concept through gamified learning environments: Insights from a longitudinal study. International Journal of Educational Research, 101, 101561 https://doi.org/10.1016/j.ijer.2020.101561

Alvermann, D. E., Hutchins, R. J., \& McDevitt, R. (2012). Adolescents' engagement with web 2.0 and social media: Research, theory, and practice. Research in the Schools, 19(1), 33-44.

Ananiadou, S., Rea, B., Okazaki, N., Procter, R., \& Thomas, J. (2009). Supporting systematic reviews using text mining. Social Science Computer Review, 27(4), 509-523 https://doi.org/10.1177/08944 39309332293

Area-Moreira, M., Hernández-Rivero, V., \& Sosa-Alonso, J. J. (2016). Models of educational integration of ICTs in the classroom. Comunicar. Media Education Research Journal, 24(1) https://doi.org/10. 3916/C47-2016-08

Arrosagaray, M., González-Peiteado, M., Pino-Juste, M., \& Rodríguez-López, B. (2019). A comparative study of Spanish adult students' attitudes to ICT in classroom, blended and distance language learning modes. Computers \& Education, 134, 31-40 https://doi.org/10.1016/j.compedu.2019.01. 016

Audrin, B. (2019). Making sense of digitization: three studies on the digitization concept and its implementation in organizations (Doctoral dissertation, Université de Fribourg).

Avila, J., \& Pandya, J. Z. (2013). Critical digital literacies as social praxis: Intersections and challenges. New literacies and digital epistemologies. Volume 54. In Peter Lang New York. Peter Lang New York. 
Aviram, A., \& Eshet-Alkalai, Y. (2006). Towards a theory of digital literacy: Three scenarios for the next steps. European Journal of Open, Distance and E-Learning, 9(1).

Bergdahl, N., Nouri, J., \& Fors, U. (2020). Disengagement, engagement and digital skills in technologyenhanced learning. Education and Information Technologies, 25(2), 957-983 https://doi.org/10. 1007/s10639-019-09998-w

Blau, I., \& Shamir-Inbal, T. (2017). Digital competences and long-term ICT integration in school culture: The perspective of elementary school leaders. Education and Information Technologies, 22(3), 769-787 https://doi.org/10.1007/s10639-015-9456-7

Blayone, T. J. B., Mykhailenko, O., vanOostveen, R., \& Barber, W. (2018). Ready for digital learning? A mixed-methods exploration of surveyed technology competencies and authentic performance activity. Education and Information Technologies, 23(3), 1377-1402 https://doi.org/10.1007/ s10639-017-9662-6

Borysenko, I. V., Bykonia, O. P., Rembach, O. O., Shumna, L. P., Oliinyk, O. I., \& Anishchenko, V. O. (2020). Experience of ICT implementation in primary curriculum in Ukraine and the United Kingdom of Great Britain and Northern Ireland. Information Technologies and Learning Tools, 75(1), 42-55 https://doi.org/10.33407/itlt.v75i1.3151

Cabello-Hutt, T., Cabello, P., \& Claro, M. (2018). Online opportunities and risks for children and adolescents: The role of digital skills, age, gender and parental mediation in Brazil. New Media \& Society, 20(7), 2411-2431 https://doi.org/10.1177/1461444817724168

Campbell, E., \& Kapp, R. (2020). Developing an integrated, situated model for digital literacy in preservice teacher education. Journal of Education, 79, 18-30 https://doi.org/10.17159/2520-9868/ i79a02

Cazco, G. H. O., González, M. C., Abad, F. M., Altamirano, J. E. D., \& Mazón, M. E. S. (2016). Determining factors in acceptance of ICT by the university faculty in their teaching practice. In Proceedings of the fourth international conference on technological ecosystems for enhancing Multiculturality (pp. 139-146) https://doi.org/10.1145/3012430.3012509

Cladis, A. E. (2020). A shifting paradigm: An evaluation of the pervasive effects of digital technologies on language expression, creativity, critical thinking, political discourse, and interactive processes of human communications. E-Learning and Digital Media, 17(5), 341-364 https://doi.org/10. $1177 / 2042753017752583$

Coker, H. (2020). Why does digital learning matter? Digital competencies, social justice and critical pedagogy in initial teacher education. Journal of teaching and learning, 14(1), 133-141. https://doi. org/10.22329/jtl.v14i1.6259

Cole, D., Rengasamy, E., Batchelor, S., Pope, C., Riley, S., \& Cunningham, A. M. (2017). Using social media to support small group learning. BMC Medical Education, 17(1), $201 \mathrm{https} / /$ doi.org/10. 1186/s12909-017-1060-7

Correa, T. (2016). Digital skills and social media use: How Internet skills are related to different types of Facebook use among 'digital natives.' Information, Communication \& Society, 19(8), 1095-1107. https://doi.org/10.1080/1369118X.2015.1084023.

Ćurlin, T., Jaković, B., \& Miloloža, I. (2019). Twitter usage in tourism: Literature review. Business Systems Research : International Journal of the Society for Advancing Innovation and Research in Economy, 10(1), 102-119.

Daley, S. G., Xu, Y., Proctor, C. P., Rappolt-Schlichtmann, G., \& Goldowsky, B. (2020). Behavioral engagement among adolescents with Reading difficulties: The role of active involvement in a universally designed digital literacy platform. Reading \& Writing Quarterly, 36(3), 278-295 https:// doi.org/10.1080/10573569.2019.1635545

de Mesa, J. C., \& Jacinto, L. G. (2020). Facebook groups as social intervention tools for improving digital skills. Social Work Education, 39(1), 71-84. https://doi.org/10.1080/02615479.2019.1642867.

Dennen, V. P., Choi, H., \& Word, K. (2020). Social media, teenagers, and the school context: A scoping review of research in education and related fields. Educational Technology Research and Development, 68(4), 1635-1658 https://doi.org/10.1007/s11423-020-09796-Z

Di Giacomo, D., Ranieri, J., \& Lacasa, P. (2017). Digital learning as enhanced learning processing? Cognitive evidence for new insight of smart learning. Frontiers in psychology, 8. https://doi.org/10. 3389/fpsyg.2017.01329.

Dixon, E. (2010). Building a model for online distance courses through social media and networks. International Journal of Virtual and Personal Learning Environments, 3(3), 81-94 https://doi.org/10. 4018/jvple.2012070105 
Durach, C. F., Kembro, J., \& Wieland, A. (2017). A new paradigm for systematic literature reviews in supply chain management. Journal of Supply Chain Management, 53(4), 67-85 https://doi.org/10. $1111 /$ jscm. 12145

Durak, H. Y., \& Seferoğlu, S. S. (2020). Antecedents of social media usage status: Examination of Predictiveness of digital literacy, academic performance, and fear of missing out variables. Social Science Quarterly, 101(3), 1056-1074 https://doi.org/10.1111/ssqu.12790

Dzhurylo, A. Р., \& Шпарик, О. (2019). ICT competence for secondary school teachers and students in the context of education informatization: Experience and challenges for Ukraine. Information Technologies and Learning Tools, 70(2), 43-58 https://doi.org/10.33407/itlt.v70i2.2438

Eshet, Y. (2004). Digital literacy: A conceptual framework for survival skills in the digital era. Journal of Educational Multimedia and Hypermedia, 13(1), 93-106.

European Commission. (2020, February 18). The European digital strategy [text]. Shaping Europe's Digital Future - European Commission. https://ec.europa.eu/digital-single-market/en/content/europ ean-digital-strategy

Eynon, R. (2020). Becoming digitally literate: Reinstating an educational lens to digital skills policies for adults. British educational research journal, $n / a(\mathrm{n} / \mathrm{a})$. https://doi.org/10.1002/berj.3686.

Eynon, R., \& Geniets, A. (2016). The digital skills paradox: How do digitally excluded youth develop skills to use the internet? Learning. Media and Technology, 41(3), 463-479 https://doi.org/10. 1080/17439884.2014.1002845

Fabbri, S., Hernandes, E., Di Thommazo, A., Belgamo, A., Zamboni, A., \& Silva, C. (2013). Using information visualization and text mining to facilitate the conduction of systematic literature reviews. In J. Cordeiro, L. a. Maciaszek, \& J. Filipe (Eds.), Enterprise information systems (Vol. 141, pp. 243-256). Springer . https://doi.org/10.1007/978-3-642-40654-6_15.

Fernández-Cruz, F. J., \& Fernández-Díaz, M. J. (2016). Generation z’s teachers and their digital skills. Comunicar, 24(46), undefined-undefined. https://doi.org/10.3916/C46-2016-10.

Ferreira-Mello, R., André, M., Pinheiro, A., Costa, E., \& Romero, C. (2019). Text mining in education. WIREs Data Mining and Knowledge Discovery, 9(6), e1332 https://doi.org/10.1002/widm.1332

Fieldhouse, M., \& Nicholas, D. (2008). Digital literacy as information savvy: The road to information literacy. In C. Lankshear \& M. Knobel (Eds.), digital literacies: Concepts, policies and practices (Peter Lange).

Gilster, P. (1997). Digital literacy. Wiley Computer Pub.

Gómez-García, M., Hossein-Mohand, H., Trujillo-Torres, J. M., \& Hossein-Mohand, H. (2020). The training and use of ICT in teaching perceptions of Melilla's (Spain) mathematics teachers. Mathematics, 8(10), 1641 https://doi.org/10.3390/math8101641

Gómez-Trigueros, I. M., Ruiz-Bañuls, M., \& Ortega-Sánchez, D. (2019). Digital literacy of teachers in training: Moving from ICTs (information and communication technologies) to LKTs (learning and knowledge technologies). Education Sciences, 9(4), 274 https://doi.org/10.3390/educsci9040274

Gudmundsdottir, G. B., Gassó, H. H., Rubio, J. C. C., \& Hatlevik, O. E. (2020). Student teachers' responsible use of ICT: Examining two samples in Spain and Norway. Computers \& Education, 152, 103877 https://doi.org/10.1016/j.compedu.2020.103877

Gui, M., \& Argentin, G. (2011). Digital skills of internet natives: Different forms of digital literacy in a random sample of northern Italian high school students. New Media \& Society, 13(6), 963-980 https://doi.org/10.1177/1461444810389751

Guillén-Gámez, F. D., Lugones, A., \& Mayorga-Fernández, M. J. (2019). ICT use by pre-service foreign languages teachers according to gender, age and motivation. Cogent Education, 6(1), 1574693 https://doi.org/10.1080/2331186X.2019.1574693

Handley, F. (2018). Developing digital skills and literacies in UK higher education: Recent developments and a case study of the digital literacies framework at the University of Brighton, UK. Publicaciones, 48(1), 109-126 https://doi.org/10.30827/publicaciones.v48i1.7327

Hardy, A., \& McKenzie, C. (2020). Meeting students where they are: Just in time embedded delivery of information and digital literacy skills. International Information \& Library Review, 52(1), 64-72 https://doi.org/10.1080/10572317.2019.1710672

Hatlevik, O. E. (2017). Examining the relationship between teachers' self-efficacy, their digital competence, strategies to evaluate information, and use of ICT at school. Scandinavian Journal of Educational Research, 61(5), 555-567 https://doi.org/10.1080/00313831.2016.1172501

Hatlevik, O. E., Ottestad, G., \& Throndsen, I. (2015). Predictors of digital competence in 7th grade: A multilevel analysis. Journal of Computer Assisted Learning, 31(3), 220-231 https://doi.org/10. 1111/jcal.12065 
Higgins, S. (2014). Critical thinking for 21st-century education: A cyber-tooth curriculum? Prospects: Quarterly Review of Comparative Education, 44(4), 559-574 https://doi.org/10.1007/ s11125-014-9323-0

Ignatow, G., \& Mihalcea, R. (2018). An introduction to text : Research Design, Data Collection, and Analysis. SAGE Publications, Inc. https://doi.org/10.4135/9781506336985.

Jara, I., Claro, M., Hinostroza, J. E., San Martín, E., Rodríguez, P., Cabello, T., Ibieta, A., \& Labbé, C. (2015). Understanding factors related to Chilean students' digital skills: A mixed methods analysis. Computers \& Education, 88, 387-398 https://doi.org/10.1016/j.compedu.2015.07.016

Jede, A., \& Teuteberg, F. (2015). Integrating cloud computing in supply chain processes: A comprehensive literature review. Journal of Enterprise Information Management.

Juhaňák, L., Zounek, J., Záleská, K., Bárta, O., \& Vlčková, K. (2019). The relationship between the age at first computer use and students' perceived competence and autonomy in ICT usage: A mediation analysis. Computers \& Education, 141, 103614 https://doi.org/10.1016/j.compedu.2019.103614

Kivunja, C. (2014). Do you want your students to be job-ready with 21 st century skills? Change pedagogies: A pedagogical paradigm shift from Vygotskyian social constructivism to critical thinking, problem solving and Siemens' digital Connectivism. International Journal of Higher Education, 3(3), 81-91.

Knight, J., Dooly, M., \& Barberà, E. (2020). Getting smart: Towards critical digital literacy pedagogies. Social Semiotics, O(0), 1-24. https://doi.org/10.1080/10350330.2020.1836815.

Lavissière, A., Sohier, R., \& Lavissière, M. C. (2020). Transportation systems in the Arctic: A systematic literature review using textometry. Transportation Research Part A: Policy and Practice, 141, 130-146 https://doi.org/10.1016/j.tra.2020.09.003

Liesa-Orús, M., Latorre-Cosculluela, C., Vázquez-Toledo, S., \& Sierra-Sánchez, V. (2020). The technological challenge facing higher education professors: Perceptions of ICT tools for developing 21st century skills. Sustainability, 12(13), 5339 https://doi.org/10.3390/su12135339

List, A. (2019). Defining digital literacy development: An examination of pre-service teachers' beliefs. Computers \& Education, 138, 146-158 https://doi.org/10.1016/j.compedu.2019.03.009

Livingstone, S., Ólafsson, K., Helsper, E. J., Lupiáñez-Villanueva, F., Veltri, G. A., \& Folkvord, F. (2017). Maximizing opportunities and minimizing risks for children online: The role of digital skills in emerging strategies of parental mediation. Journal of Communication, 67(1), 82-105 https://doi.org/10.1111/jcom.12277

Lorenz, R., Endberg, M., \& Bos, W. (2019). Predictors of fostering students' computer and information literacy - Analysis based on a representative sample of secondary school teachers in Germany. Education and Information Technologies, 24(1), 911-928 https://doi.org/10.1007/ s10639-018-9809-0

Martín, S. C., González, M. C., \& Peñalvo, F. J. G. (2020). Digital competence of early childhood education teachers: Attitude, knowledge and use of ICT. European Journal of Teacher Education, 43(2), 210-223 https://doi.org/10.1080/02619768.2019.1681393

Mirete, A. B., Maquilón, J. J., Mirete, L., \& Rodríguez, R. A. (2020). Digital competence and university teachers' conceptions about teaching. A structural causal model. Sustainability, 12(12), 4842. https://doi.org/10.3390/su12124842.

Moher, D., Shamseer, L., Clarke, M., Ghersi, D., Liberati, A., Petticrew, M., Shekelle, P., \& Stewart, L. A. (2015). Preferred reporting items for systematic review and meta-analysis protocols (PRISMAP) 2015 statement. Systematic Reviews, 4(1), 1 https://doi.org/10.1186/2046-4053-4-1

Mynaříková, L., \& Novotný, L. (2020). Knowledge society failure? Barriers in the use of ICTs and further teacher education in the Czech Republic. Sustainability, 12(17), 6933 https://doi.org/10.3390/ su12176933

Ng, W. (2012). Can we teach digital natives digital literacy? Computers \& Education, 59(3), 1065-1078 https://doi.org/10.1016/j.compedu.2012.04.016.

Novakovich, J. (2016). Fostering critical thinking and reflection through blog-mediated peer feedback. Journal of Computer Assisted Learning, 32(1), 16-30 https://doi.org/10.1111/jcal.12114

Nuzzaci, A. (2017, July 1). Technological skills and initial teacher training: An exploratory research on attitudes of the future teachers towards ICT [article]. Journal of Digital Literacy and Digital Competence (IJDLDC). www.igi-global.com/article/technological-skills-and-initial-teacher-train ing/199049

Pagani, L., Argentin, G., Gui, M., \& Stanca, L. (2016). The impact of digital skills on educational outcomes: Evidence from performance tests. Educational Studies, 42(2), 137-162 https://doi.org/10. $1080 / 03055698.2016 .1148588$ 
Peláez, A. L., Erro-Garcés, A., \& Gómez-Ciriano, E. J. (2020). Young people, social workers and social work education: The role of digital skills. Social Work Education, 39(6), 825-842 https://doi.org/ 10.1080/02615479.2020.1795110

Pérez-Escoda, A., Castro-Zubizarreta, A., \& Fandos-Igado, M. (2016). Digital skills in the Z generation: Key questions for a curricular introduction in primary school. Comunicar, 24(49), 71-79 https:// doi.org/10.3916/C49-2016-07

Petrucco, C., \& Ferranti, C. (2017). Developing critical thinking in online search. Journal of E-Learning and Knowledge Society, 13(3).

Picatoste, J., Pérez-Ortiz, L., \& Ruesga-Benito, S. M. (2018). A new educational pattern in response to new technologies and sustainable development. Enlightening ICT skills for youth employability in the European Union. Telematics and Informatics, 35(4), 1031-1038 https://doi.org/10.1016/j.tele. 2017.09.014

Pinto, M., Fernández-Pascual, R., Caballero-Mariscal, D., \& Sales, D. (2020). Information literacy trends in higher education (2006-2019): Visualizing the emerging field of mobile information literacy. Scientometrics, 124(2), 1479-1510 https://doi.org/10.1007/s11192-020-03523-4

Pollach, I. (2011). Software review: Wordstat 5.0. Organizational Research Methods, 14(4), 741-744.

Pombo, L., Carlos, V., \& Loureiro, M. J. (2017). Edulabs AGIRE project-Evaluation of ICT integration in teaching strategies. Educational Media International, 54(3), 215-230 https://doi.org/10.1080/ 09523987.2017.1384158

Rivera, C. J., Hudson, M. E., Weiss, S. L., \& Zambone, A. (2017). Using a multicomponent multimedia shared story intervention with an iPad to teach content picture vocabulary to students with developmental disabilities. Education and Treatment of Children, 40(3), 327-352.

Rwodzi, C., de Jager, L., \& Mpofu, N. (2020). The innovative use of social media for teaching English as a second language. The Journal for Transdisciplinary Research in Southern Africa, 16(1), 7 https:// doi.org/10.4102/td.v16i1.702

Schütze, H., Manning, C. D., \& Raghavan, P. (2008). Introduction to information retrieval (Vol. 39). Cambridge University press Cambridge.

Scuotto, V., \& Morellato, M. (2013). Entrepreneurial knowledge and digital competence: Keys for a success of student entrepreneurship. Journal of the Knowledge Economy, 4(3), 293-303 https://doi. org/10.1007/s13132-013-0155-6

Siddiq, F., Scherer, R., \& Tondeur, J. (2016). Teachers' emphasis on developing students' digital information and communication skills (TEDDICS): A new construct in 21 st century education. Computers \& Education, 92-93, 1-14 https://doi.org/10.1016/j.compedu.2015.10.006

Sillat, L. H., Kollom, K., \& Tammets, K. (2017). DEVELOPMENT OF DIGITAL COMPETENCIES IN PRESCHOOL TEACHER TRAINING. EDULEARN17 proceedings, 1806-1813.

Spante, M., Hashemi, S. S., Lundin, M., Algers, A., \& Wang, S. (2018). Digital competence and digital literacy in higher education research: Systematic review of concept use. Cogent Education, 5(1), 1519143 https://doi.org/10.1080/2331186X.2018.1519143

Stopar, K., \& Bartol, T. (2019). Digital competences, computer skills and information literacy in secondary education: Mapping and visualization of trends and concepts. Scientometrics, 118(2), 479-498 https://doi.org/10.1007/s11192-018-2990-5

Sun, C., Shute, V. J., Stewart, A., Yonehiro, J., Duran, N., \& D’Mello, S. (2020). Towards a generalized competency model of collaborative problem solving. Computers \& Education, 143, 103672 https:// doi.org/10.1016/j.compedu.2019.103672

Tejedor, S., Cervi, L., Pérez-Escoda, A., \& Jumbo, F. T. (2020). Digital literacy and higher education during COVID-19 lockdown: Spain, Italy, and Ecuador. Publications, 8(4), 48 https://doi.org/10. 3390/publications 8040048

Thomas, J., McNaught, J., \& Ananiadou, S. (2011). Applications of text mining within systematic reviews. Research Synthesis Methods, 2(1), 1-14 https://doi.org/10.1002/jrsm.27

Tømte, C. E. (2015). Educating teachers for the new millennium? - teacher training, ICT and digital competence. Nordic journal of digital literacy, 10(Jubileumsnummer), 138-154.

Tuamsuk, K., \& Subramaniam, M. (2017). The current state and influential factors in the development of digital literacy in Thailand's higher education. Information and Learning Science.

U.S. Department of Education. (2014). Digital Government Strategy Report. https://www2.ed.gov/digit alstrategy/index.html

van Deursen, A. J. A. M., \& van Dijk, J. A. G. M. (2009). Improving digital skills for the use of online public information and services. Government Information Quarterly, 26(2), 333-340 https://doi. org/10.1016/j.giq.2008.11.002 
van Dijk, J. (2006). The network society: Social aspects of new media (2nd ed). Sage Publications.

van Ingen, E., \& Matzat, U. (2018). Inequality in mobilizing online help after a negative life event: The role of education, digital skills, and capital-enhancing internet use. Information, Communication \& Society, 21(4), 481-498 https://doi.org/10.1080/1369118X.2017.1293708

van Laar, E., van Deursen, A. J. A. M., van Dijk, J. A. G. M., \& de Haan, J. (2017). The relation between 21st-century skills and digital skills: A systematic literature review. Computers in Human Behavior, 72, 577-588 https://doi.org/10.1016/j.chb.2017.03.010

van Laar, E., van Deursen, A. J. A. M., van Dijk, J. A. G. M., \& de Haan, J. (2019). Determinants of 21stcentury digital skills: A large-scale survey among working professionals. Computers in Human Behavior, 100, 93-104 https://doi.org/10.1016/j.chb.2019.06.017

Vázquez-Cano, E., León Urrutia, M., Parra-González, M. E., \& López Meneses, E. (2020). Analysis of interpersonal competences in the use of ICT in the Spanish University context. Sustainability, 12(2), 476 https://doi.org/10.3390/su12020476

Vial, G. (2019). Understanding digital transformation: A review and a research agenda. The Journal of Strategic Information Systems, 28(2), 118-144 https://doi.org/10.1016/j.jsis.2019.01.003

Vijayarani, S., Ilamathi, M. J., \& Nithya, M. (2015). Preprocessing techniques for text mining-an overview. International Journal of Computer Science \& Communication Networks, 5(1), 7-16.

Walton, G., Pickard, A. J., \& Dodd, L. (2018). Information discernment, mis-information and pro-active scepticism. Journal of Librarianship and Information Science, 50(3), 296-309 https://doi.org/10. $1177 / 0961000618769980$

Yu, T.-K., Lin, M.-L., \& Liao, Y.-K. (2017). Understanding factors influencing information communication technology adoption behavior: The moderators of information literacy and digital skills. Computers in Human Behavior, 71, 196-208 https://doi.org/10.1016/j.chb.2017.02.005

Zhong, Z.-J. (2011). From access to usage: The divide of self-reported digital skills among adolescents. Computers \& Education, 56(3), 736-746 https://doi.org/10.1016/j.compedu.2010.10.016

Publisher's note Springer Nature remains neutral with regard to jurisdictional claims in published maps and institutional affiliations. 